\title{
Homocysteine and Lipid Peroxidation in Active and Passive Smoking
}

\author{
Duangkamol Viroonudomphol ${ }^{1}$, Pornpimon Poomrittikul ${ }^{1}$, Tharntip Jirakanjana ${ }^{1}$, \\ Siriwan Tribanyatkul ${ }^{2}$, Saowanee Kanjanachumpon ${ }^{3}$ \\ ${ }^{1}$ Faculty of Nursing, Siam University, Bangkok, Thailand \\ ${ }^{2}$ Pramongkutklaw Hospital, Bangkok, Thailand \\ ${ }^{3}$ Faculty of Medicine, Ramathibodi Hospital, Mahidol University, Bangkok, Thailand
}

Email address:

v_duangkamol@yahoo.com (D. Viroonudomphol), Nok.1823@hotmail.com (P. Poommrittikul), kimmekha@gmail (T. Jirakanjana), siriwantri@hotmail.com (S. Tribanyatkul), sao_rc@yahoo.com (S. Kanjanachumpon)

\section{To cite this article:}

Duangkamol Viroonudomphol, Pornpimon Poomrittikul, Tharntip Jirakanjana, Siriwan Tribanyatkul, Saowanee Kanjanachumpon. Homocysteine and Lipid Peroxidation in Active and Passive Smoking. Science Journal of Public Health. Vol. 6, No. 2, 2018 , pp. $43-49$. doi: $10.11648 /$ j.sjph.20180602.12

Received: December 13, 2017; Accepted: January 12, 2018; Published: January 25, 2018

\begin{abstract}
Disease risk due to smoking is not limited to smokers only. Passive smoking (exposure to environmental tobacco smoke) is associated with adverse health effect especially in cardiovascular disease. Side-stream cigarette smoke, a major component of secondhand smoke induces reactive oxygen species with promote oxidative stress. This paper summarizes the cardiovascular effects of tobacco smoke. According to the results of the alternative level of biochemistry substances, Cholesterol (C), HDL- Cholesterol (HDL-C), LDL-Cholesterol (LDL-C), Triglyceride (TG), Malondialdehyde (MDA), Conjugate diene (CD), vitamin B12, folate and Homocysteine (Hcy). The results showed that vitamin B12 and Hcy of smokers were significantly higher than those of non-smokers while C, LDL-C, TG and folate were significantly lower than those of non-smokers. More detail of smoking group, the industrial tobacco smokers had HDL-C and vitamin B12 lower than those in non-smokers whereas passive smokers and local handmade tobacco smokers had serum HDL-C and vitamin B12 higher than those in non-smokers. For serum C, LDL-C, TG and folate of all groups of smokers were significantly lower than nonsmokers. The industrial tobacco smokers had serum MDA significantly higher than non-smokers but passive smokers and local handmade tobacco smokers had serum MDA lower than non-smokers. The industrial tobacco smokers and passive smokers had serum Hcy significantly higher than non-smokers but local handmade tobacco smokers had serum Hcy lower than nonsmokers.
\end{abstract}

Keywords: Homocysteine, Lipid Peroxidation, Active and Passive Smoking

\section{Introduction}

In 2015, over 1.1 billion people smoked tobacco. Far more males than females smoked tobacco. Although it is declining worldwide and in many countries, the prevalence of tobacco smoking appears to be increasing in the African region. It is estimated that this number will be 1.6 billion in 2025 . The number of smokers will increase in Third World countries from 4.5 billion to 7.1 billion by 2025 [1]. The World Health Organization reports that tobacco kill up to its users. Tobacco kills nearly 6 million people each year. More than 5 million of these deaths are the result of direct tobacco use while more than 600,000 are the result of non-smokers being exposed to second-hand smoke. Unless urgent action is taken, the annual death could rise to more than 8 million by 2030 . Nearly $80 \%$ of the world's one billion smokers live in low-and middleincome countries [2]. The World Bank estimates that, in high income countries, smoking-related health care accounts have been health-care costs [3]. Both active and passive smoking are associated with an increased risk of coronary heart disease [4-5] and cancer. A number of mechanisms may be involved in the atherogenesis by passive smoking, such as dysfunction of endothelium [6], altered lipoprotein profiles [7], increase the concentration of serum total choleaterol (C), 
triglycerides (TG), low-density lipoprotein cholesterol (LDLC), very low-density lipoprotein cholesterol (VLDL-C) and decrease the levels of antiatherogenic high-density lipoprotein cholesterol (HDL-C) [8]. Passive smoking could affect blood lipid metabolism in women, which might contribute to coronary heart disease [9]. A positive association between elevated plasma homocysteine levels and a number of cardiovascular risk factors, smoking, particularly, was shown, in a study conducted in Norway [10]. Smokers (male and female) had significantly lower high-density lipoprotein levels and significantly higher very low-density lipoprotein, total cholesterol and plasma triglyceride levels than nonsmokers [11]. Smokers also tend to have lower levels of folate, vitamin B6, and vitamin B12 $[12,13]$. The pioneer studies on the relationship between the homocysteine and atherosclerosis were carried out by Kilmer McCully [14]. The mechanism of homocysteine on blood vessels proposed by the investigator is still accepted and new supporting evidence is increasing. Naruszenewicz et al., [15] supporting evidence have proved that homocysteine thiolactone modifies low-density lipoproteins through binding to apoolipoprotein B free lysine groups, which results in increased LDL aggregation and generation of foam cells. It is not only reported that active smoking was associated with increased lipid peroxides in plasma, but also that passive smoking that affected plasma lipidperoxidation [15]. Smokers also tend to have lower levels of folate, vitamin B6, and vitamin B12 $[12,13]$ which are cofactors (vitamins B6 and B12) or cosubstrates (folate) for enzymes that control homocysteine metabolism [16, 17]. Side-stream cigarette smoke is a major component of second-hand smoke, which contains thousands of chemical constituents [18]. The toxicity of tobacco inducers of reactive oxygen species (ROS) that promote oxidative damage [19]. Free radicals disturb biological systems by reacting with a variety of their constituent molecules. Lipids and intermediate lipid metabolites are one of the potential targets for the oxidative attack of radical. Epidemiologic studies demonstrated an increase in coronary artery disease risk and mortality with exposure to secondhand smoke [20].

The present study examined not only vitamin B12, folate, levels of homocysteine but also leukocyte, platelet counts and lipid profiles such as the levels of serum total cholesterolo, HDL-C, LDL-C, TG, malondialdehyde (MDA) and conjugate diene (CD) in healthy Thai smokers and passive smokers exposure in non-smokers compared with non-smokers.

\section{Materials and Methods}

Subjects of this study consisted of 100 male smokers and 50 passive smokers (50 industrial tobacco smokers, 50 passive smokers from a military unit of Phramongkutklaw Hospital and College of Medicine in Bangkok, and 50 self local handmade tobacco smokers from a village in Phitsanulok) compared with 50 male who self reported as never-smokers from the same military unit were selected as nonsmoking controls. The subjects were participated in the study between April to September 2009. This study protocol was approved by the Ethics Committee of Phramongkutklaw Hospital and College of Medicine for Health Statistics and informed consent was obtained before participation. The age, marital status, socio-economic status, drinking, smoking and medicines, including past and present illnesses, were assessed through standardized questionnaires.

All subjects were fasted and were took to venous blood about $20 \mathrm{ml}$ in the morning, and centrifuged serum at 4000 rpm. Heparinised blood was used to analyze haematological variables and serum blood was used to determine for lipid profiles such as C, HDL-C, LDL-C and TG.

A serum aliquot was stored frozen at $-80^{\circ} \mathrm{C}$ for vitamin B12, folate, MDA, (reacts with thiobarbituric acid to give red species absorbing at $535 \mathrm{~nm}$ [21], CD [22] and homocysteine then analyzed within 1 month of collection to ensure the stability of the compounds.

Laboratory techniques

Haemoglobin $(\mathrm{Hb})$ concentrations in whole blood were used to determine by using the modified cyanmethaemoglobin method. The haematocrit $(\mathrm{Hct})$ values were analyzed by a micro-method using calibrated heparinised capillary tubes. The capillary with blood were centrifuged at $14000 \mathrm{~g}$ for $5 \mathrm{~min}$ then the Hct values were read using a micro-haematocrit reader (Hawksleye Son Ltd, Marlborough, UK). Platelets in peripheral blood smears were counted using the method of Nosanchuk et al. [23]. Reticulocytes were counted under an oil-immersion lens. The morphology of both red and white blood cells (WBC) was determined using the Wedge method. A commercially available Boehringer Mannheim (Germany) test kit was used to determine C, HDL-C, LDL-C and TG. The values of $\geq$ $5.18 \mathrm{mmoll}^{-1}$ and $6.48 \mathrm{mmoll}^{-1}$ of cholesterol, $\geq 3.98 \mathrm{mmoll}^{-1}$ of LDL-C,$\leq 0.91 \mathrm{mmoll}^{-1}$ of HDL-C and $\geq 2.26 \mathrm{mmoll}^{-1}$ of TG were taken as cut-off points. Serum vitamin B12 and folate were measured by using radioimmunoassay commercial kits (Dualcount solid phase no boil assay for vitamin B12, folate, Diagnostic Products Corporation, Los Angeles, CA, USA). The reduced of vitamin B12 and folate levels were defined as a concentration $<200$ pmoll $^{-1}$ and 6.79 $\mathrm{nmoll}^{-1}$, respectively. Homocysteine levels were measured using automated fluorescence polarization immunoassay. An elevated homocysteine level was defined as a concentration $>15 \mu$ moll $^{-1}$.

Statistical analysis

All data were checked for the distribution. There were abnormal distribution, the results were expressed as median, range and 95\% confidence interval (CI) and nonparametric statistical analysis were calculated. The Mann Whitney U-Wilcoxon Rank Sum W-test (two tailed) was used to compare the statistical differences between groups for continuous variables. The statistical analyses were performed by using software program SPSS 17.0 for Windows (SPSS Inc., Chicago, IL, USA) was used for these computations. 


\section{Results}

The distribution of smokers according to the quantity of cigarettes smoked was shown in Table 1 and the characteristics of the participants both smokers and nonsmokers were shown in Table 2.

Table 1. Distribution of smokers according to the quantity of cigarettes smoked for the whole period of smoking (units in \% number of cigarette smoked per day multiplied by duration of smoking years).

\begin{tabular}{ll}
\hline Quantity of cigarettes smoked (cigarette-years) & \% \\
\hline $1-5$ & 24 \\
$6-10$ & 26 \\
$11-15$ & 23 \\
$16-20$ & 19 \\
$>21$ & 8 \\
\hline
\end{tabular}

Table 2. Descriptive data and characteristics of the study sample in relation to smoking status.

\begin{tabular}{|c|c|c|c|}
\hline Age (year) & Smokers n (\%) & Non-smokers n (\%) & p-value \\
\hline $18-30$ & $50 / 150(30.3)$ & $16 / 50(32.0)$ & NS \\
\hline $31-40$ & $30 / 150(20.0)$ & $13 / 50(26.0)$ & NS \\
\hline $41-50$ & $30 / 150(20.0)$ & $11 / 50(22.0)$ & NS \\
\hline$>60$ & $20 / 150(13.3)$ & - & \\
\hline \multicolumn{4}{|l|}{ Education } \\
\hline Primary & $18 / 150(12.0)$ & $1 / 50(2.0)$ & 0.008 \\
\hline Vocation & $10 / 150(6.7)$ & $14 / 50(28.0)$ & 0.018 \\
\hline Undergraduate/postgraduate & $50 / 150(33.3)$ & $30 / 50(60.0)$ & 0.032 \\
\hline \multicolumn{4}{|l|}{ Marital status } \\
\hline Single & $54 / 150(36.0)$ & $13 / 50(26.0)$ & NS \\
\hline Married & $90 / 150(60.0)$ & $35 / 50(70.0)$ & NS \\
\hline Widow & $5 / 150(3.3)$ & $1 / 50(2.0)$ & NS \\
\hline Divorced & $1 / 150(0.7)$ & $1 / 50(2.0)$ & NS \\
\hline \multicolumn{4}{|l|}{ Alcohol drinking } \\
\hline Drink & $100 / 150(66.7)$ & $23 / 50(46.0)$ & 0.018 \\
\hline Give up & $8 / 150(5.3)$ & $5 / 50(10.0)$ & 0.042 \\
\hline
\end{tabular}

The median and $95 \%$ confidence interval (CI) of age, weight, height, BMI, blood pressure, hematological measurements, lipid profiles, vitamins and homocysteine in smokers (industrial tobacco Smokers, passive smokers, local handmade tobacco smokers) and non-smokers are shown in table 2. BMI was found to have the tendency to be significantly lower in all group smokers compared with nonsmokers. SBP and DBP were significantly lower in all group smokers with the exception of local handmade tobacco smokers which were found to be higher than non-smokers.

$\mathrm{Hb}$, Hct and Mean corpuscular haemoglobin concentration (MCHC) in smokers were slightly and significantly lower than in non-smokers. Mean corpuscular haemoglobin (MCH) and mean corpuscular volume (MCV) of smokers were not statistically significantly different from those of nonsmokers.

Serum total C, LDL-C and TG in all groups of smoker were statistically significantly lower than non-smokers.
MDA levels were lower among smokers than controls except the industrial tobacco smokers. No significant differences of HDL- C and CD were found between smokers and nonsmokers. Serum folate concentrations of all groups smoker were statistically significantly lower than non-smokers, but not statistically significantly different in passive smokers. Serum vitamin B12 levels were statistically significantly higher in the total smokers than the non-smokers. Only the industrial tobacco smokers group had vitamin B12 lower than non-smoker. The highest serum vitamin B12 levels were found in local handmade tobacco smokers. Hcy levels in all groups of smoker except the local handmade tobacco smokers were higher than non-smokers. In addition the smokers had a significantly higher white blood cell count than the non-smokers whereas serum folate levels were statistically significantly lower in the total smokers than the non-smokers (Table 3).

Table 3. Median, range and 95\% confidence interval (CI) of age, weight, height, BMI, blood preasure, hematological measurements, lipid profiles, MDA, CD, vitamin B12, folate and homocysteine in smokers, passive smokers and non-smokers.

\begin{tabular}{|c|c|c|c|c|c|}
\hline \multirow{3}{*}{ Variable } & \multicolumn{4}{|l|}{ Smokers } & \multirow[b]{2}{*}{$\begin{array}{l}\text { Non-smokers } \\
(n=50)\end{array}$} \\
\hline & $\begin{array}{l}\text { Industrial Tobacco } \\
\text { Smokers }(n=50) \\
\end{array}$ & $\begin{array}{l}\text { Passive Smokers } \\
(n=50)\end{array}$ & $\begin{array}{l}\text { local handmade tobacco } \\
\text { smokers }(n=50)\end{array}$ & Total $(n=150)$ & \\
\hline & Median (95\% CI) & Median $(95 \%$ CI $)$ & Median $(95 \%$ CI) & Median (95\% CI) & Median (95\% CI) \\
\hline Age (years) & $21.0 \mathrm{bd}(18.0-24.5)$ & 21.0 ce $(19.0-24.5)$ & $50.0 f(47.6-54.4)$ & $40.0(38.0-42.0)$ & $37.0(32.0-42.0)$ \\
\hline Weight (kg) & $57.9 \mathrm{a}(55.5-60.79)$ & $63.3 \mathrm{e}(60.0-66.5)$ & $56.0 \mathrm{f}(54.9-60.5)$ & $62.5(59.3-65.6)$ & $69.0(66.5-73.3)$ \\
\hline
\end{tabular}




\begin{tabular}{|c|c|c|c|c|c|}
\hline \multirow{3}{*}{ Variable } & \multicolumn{4}{|l|}{ Smokers } & \multirow{2}{*}{$\begin{array}{l}\text { Non-smokers } \\
(\mathrm{n}=50)\end{array}$} \\
\hline & $\begin{array}{l}\text { Industrial Tobacco } \\
\text { Smokers }(\mathbf{n}=\mathbf{5 0})\end{array}$ & $\begin{array}{l}\text { Passive Smokers } \\
(\mathrm{n}=50)\end{array}$ & $\begin{array}{l}\text { local handmade tobacco } \\
\text { smokers }(n=50)\end{array}$ & Total $(n=150)$ & \\
\hline & Median (95\% CI) & Median (95\% CI) & Median $(95 \%$ CI) & Median $(95 \%$ CI) & Median $(95 \% \mathrm{CI})$ \\
\hline Height $(\mathrm{cm})$ & $170(161.5-178.5)$ & $169(160.5-177.4)$ & $165 f(126.7-173.2)$ & $168(159.6-176.4)$ & $170(163.0-177.0)$ \\
\hline $\operatorname{BMI}\left(\mathrm{kg} / \mathrm{m}^{2}\right)$ & $20.29 \mathrm{ad}(19.27-21.31)$ & $22.34 \mathrm{ce}(21.3-24.3)$ & $21.08 f(20.29-22.07)$ & $20.97(19.92-22.02)$ & $23.5 *(22.93-24.75$ \\
\hline $\begin{array}{l}\text { Systolic blood pressure } \\
(\mathrm{mmHg})\end{array}$ & 110abd (104.5-115.5) & $119 \mathrm{c}(113.0-124.9)$ & $128 \mathrm{f}(124.3-133.1)$ & $119(113.5-124.5)$ & $120(116.1-124.2)$ \\
\hline $\begin{array}{l}\text { Diastolic blood pressure } \\
(\mathrm{mmHg})\end{array}$ & 64abd (60.8-67.2) & $71 \mathrm{c}(67.4-74.5)$ & $81(77.6-83.4)$ & $72(68.4-75.6)$ & $78(75.2-80.3)$ \\
\hline $\mathrm{Hb}\left(\mathrm{gdl}^{-1}\right)$ & 13.2abd (12.5-13.9) & $14.3(13.5-15.9)$ & $14.6(14.1-14.9)$ & $13.2(12.5-13.9)$ & $14.6 *(14.2-14.8)$ \\
\hline Hct (\%) & 0.421 abd $(0.400-0.442)$ & $0.435 \mathrm{e}(0.413-0.456)$ & $0.450(0.413-0.456)$ & $0.430(0.423-0.438)$ & $\begin{array}{l}0.445 *(0.432- \\
0.450)\end{array}$ \\
\hline $\operatorname{MCHC}\left(\mathrm{gdl}^{-1}\right)$ & 31.6abd (30.0-33.2) & $32.6(30.9-34.2)$ & $32.9(30.9-34.2)$ & $32.6(32.2-32.8)$ & $33.0(32.8-42.2)$ \\
\hline $\mathrm{MCH}(\mathrm{pg})$ & $27.9(27.5-28.8)$ & $27.6(26.7-29.0)$ & $27.6(26.7-29.0)$ & $28.4(27.5-28.8)$ & $28.3(27.6-28.6)$ \\
\hline MCV (fl) & 88.4ad (84.0-92.8) & $84.2(81.6-87.4)$ & $83.8(80.3-86.8)$ & $86.3(81.6-87.4)$ & $85.5(84.0-86.5)$ \\
\hline WBC count $\left(\operatorname{cell} \mu 1^{-1}\right)$ & $7000(6500-7385)$ & $6700(6365-7035)$ & $7000(6500-7385)$ & $7000(6500-7385)$ & $6300 *(5800-6848)$ \\
\hline Platelet count $\left(\operatorname{cell} \mu 1^{-1}\right)$ & $277300(263400-291200)$ & $\begin{array}{l}254600(241800- \\
268000)\end{array}$ & $246600(234000-259200)$ & $\begin{array}{l}255000(243000- \\
268392)\end{array}$ & $\begin{array}{l}250500(238601- \\
264890)\end{array}$ \\
\hline Total Cholesterol $\left(\mathrm{mmoll}^{-1}\right)$ & 143abd (135.8-150.1) & 165 ce $(156.7-173.2)$ & $183 \mathrm{f}(174.0-192.5)$ & $164(155.8-172.2)$ & $204 *(191.8-216.8)$ \\
\hline $\operatorname{HDL}-\mathrm{C}\left(\mathrm{mmoll}^{-1}\right)$ & $46 \mathrm{~b}(44.2-48.8)$ & $49(46.5-51.4)$ & $53(49.6-57.4)$ & $49(46.6-51.3)$ & $48(45.6-50.1)$ \\
\hline LDL-C $\left(\mathrm{mmoll}^{-1}\right)$ & 83abd (78.8-87.1) & $90.9 \mathrm{e}(86.3-95.4)$ & $108 \mathrm{f}(97.6-116.2)$ & $95.2(90.4-100.0)$ & $131 *(124.4-137.5)$ \\
\hline $\mathrm{TG}\left(\mathrm{mmoll}^{-1}\right)$ & 71abd (67.4-74.5) & $79 \mathrm{ce}(75.0-82.9)$ & $121(91.9-151.6)$ & $112(106.4-117.6)$ & $134 *(127.3-140.7)$ \\
\hline $\operatorname{MDA}\left(\mathrm{mmoll}^{-1}\right)$ & $2.87 \mathrm{abd}(1.78-1.96)$ & $2.28(2.17-2.39)$ & $2.16(2.06-2.26)$ & $2.16(2.04-2.27)$ & $2.3(2.18-2.41)$ \\
\hline $\mathrm{CD}$ & $0.135(0.128-0.140)$ & $0.140(0.133-0.147)$ & $0.14(0.120-0.160)$ & $0.14(0.13-0.15)$ & $0.17(0.16-0.18)$ \\
\hline Vitamin B12 (pmoll-1 $)$ & $385.8 \mathrm{~b}(366.51-405.09)$ & $\begin{array}{l}434.00 \mathrm{c}(412.30- \\
455.70)\end{array}$ & $754.9 f(717.15-792.64)$ & $516.0(490.2-541.8)$ & $\begin{array}{l}409.22 *(388.76- \\
429.68)\end{array}$ \\
\hline Serum folate $\left(\mathrm{nmoll}^{-1}\right)$ & 5.28abd (5.02-5.54) & $6.39(6.07-6.71)$ & $6.31 \mathrm{f}(5.99-6.62)$ & $6.12(5.6-7.01)$ & $7.84 *(5.8-9.1)$ \\
\hline Homocysteine $\left(\mu\right.$ moll $\left.^{-1}\right)$ & 15.33ad (14.56-16.10) & $17.71 \mathrm{ce}(16.82-18.6)$ & $13.84(12.35-15.33)$ & $15.3(13.15-16.84)$ & $\begin{array}{l}14.48 *(11.75- \\
15.20)\end{array}$ \\
\hline
\end{tabular}

$\mathrm{Hb}=$ Heamoglobin; $\mathrm{Hct}=$ Heamatocrit; $\mathrm{MCHC}=$ Mean corpuscular haemoglobin concentration

$\mathrm{MCH}=\mathrm{Mean}$ corpuscular haemoglobin; $\mathrm{MCV}=$ Mean corpuscular volume; $\mathrm{WBC}=$ White blood cell

HDL-C $=$ High density lipoprotein cholesterol; LDL-C $=$ Low density lipoprotein cholesterol; $\mathrm{TG}=$ Triglyceride

$\mathrm{MDA}=$ Malondialdehyde; $\mathrm{CD}=$ Conjugate diene

$\mathrm{a}=$ significant between Industrial Tobacco Smokers and Passive Smokers

$\mathrm{b}=$ significant between Industrial Tobacco Smokers and local handmade tobacco smokers

$\mathrm{c}=$ significant between Passive Smokers and local handmade tobacco smokers

$\mathrm{d}=$ significant between Industrial Tobacco Smokers and non-smokers

$\mathrm{e}=$ significant between Passive Smokers and non-smokers

$\mathrm{f}=$ significant between local handmade tobacco smokers and non-smokers

*= significant between total smokers and non-smokers

Table 4. Proportion of subjects with abnormal variables of haematological parameters, vitamin B12, folate, homocysteine, blood pressure and lipid profiles in smokers and non-smokers.

\begin{tabular}{|c|c|c|c|c|c|c|}
\hline \multirow{2}{*}{ Variable } & \multicolumn{2}{|l|}{ Smokers } & \multicolumn{2}{|c|}{ Non-smokers } & \multirow{2}{*}{ Odds ratio } & \multirow{2}{*}{$P$-value } \\
\hline & n & $\%$ & $n$ & $\%$ & & \\
\hline Heamoglobin & $36 / 150$ & 24.2 & $2 / 50$ & 4.0 & 6.00 & 0.006 \\
\hline Heamatocrit & $29 / 150$ & 19.3 & $2 / 50$ & 4.0 & 4.83 & 0.010 \\
\hline $\mathrm{MCHC}$ & $10 / 150$ & 6.7 & $4 / 50$ & 8.0 & 0.83 & NS \\
\hline Serum B12 & $43 / 150$ & 28.7 & $4 / 50$ & 8.0 & 3.58 & 0.008 \\
\hline Serum folate & $47 / 150$ & 31.3 & $0 / 50$ & 0.0 & 0.00 & - \\
\hline Homocysteine & $56 / 150$ & 37.6 & $10 / 50$ & 20.0 & 1.87 & 0.017 \\
\hline $\mathrm{SBP} \geq 160 \mathrm{mmHg}$ & $3 / 150$ & 2.0 & $0 / 50$ & 0.0 & - & - \\
\hline $\mathrm{DBP} \geq 95 \mathrm{mmHg}$ & $16 / 150$ & 10.7 & $3 / 50$ & 6.0 & 1.78 & 0.019 \\
\hline Cholesterol $\geq 5.18$ & $25 / 150$ & 16.7 & $30 / 50$ & 60.0 & 0.28 & NS \\
\hline HDL-C $\leq .0 .91$ & $15 / 150$ & 10.0 & $4 / 50$ & 8.0 & 1.25 & NS \\
\hline LDL-C $\geq 3.89$ & $11 / 150$ & 7.3 & $4 / 50$ & 8.0 & 0.91 & NS \\
\hline $\mathrm{TG} \geq 2.26$ & $14 / 150$ & 9.3 & $7 / 50$ & 14.0 & 0.67 & NS \\
\hline
\end{tabular}

$\mathrm{MCHC}=$ Mean corpuscular haemoglobin concentration; $\mathrm{TG}=$ Triglyceride; $\mathrm{SBP}=$ Systolic blood pressure; $\mathrm{DBP}=$ Diastolic blood pressure; HDL-C $=$ High density lipoprotein cholesterol; $\mathrm{LDL}-\mathrm{C}=$ Low density lipoprotein cholesterol; $\mathrm{MDA}=$ Malondialdehyde; $\mathrm{CD}=\mathrm{Conjugate}$ diene

Table 4 shows the proportion of smokers and non-smokers who had the abnormal haematological parameters, vitamin B12, folate deficiency, hyperhomocysteinemia, hypertension and abnormal lipid profiles. $24.2 \%$ of smokers were anaemic compared with $4 \%$ of non-smokers using a haemoglobin concentration below $13.0 \mathrm{~g} \mathrm{dl}^{-1}$ as the cut-off point. The odds ratio was 6.00 which means that the smokers had 6 times significantly higher risk for anaemia that non-smokers. Of 
smokers, $19.3 \%$ and $4 \%$ of non-smokers had a haematocrit below the cut-off point of 0.4 . According to their MCHC, $6.7 \%$ of smokers and $8.0 \%$ of non-smokers had MCHC below the cut-off point of $33 \mathrm{~g} \mathrm{dl}^{-1}$ (Table 3). Regarding serum vitamin B12 deficiency, 43 out of 150 (28.7\%) of the smokers and 4 out of $50(8.0 \%)$ of the non-smokers had serum vitamin B12 levels below the cut-off point of 150 pmoll $^{-1}$ (203 $\mathrm{pgml}^{-1}$, conversion factor 0.737 ) [15]. 31.3\% of smokers had serum folate levels below the cut-off point of 10 nmol ${ }^{-1}\left(4 \mathrm{ngml}^{-1}\right.$, conversion factor 2.265) [16] $(\mathrm{P}=0.026)$ (Table 3). $37.6 \%$ of smokers and $20 \%$ of non-smokers had hyperhomocysteinemia above the cut-off point of $15 \mu \mathrm{moll}^{-1}$ [16]. For hypertension, 2\% SBP and $10.7 \%$ DBP of smokers had the levels above the cut-off point $\mathrm{SBP} \geq 160 \mathrm{mmHg}$ and DBP $>95 \mathrm{mmHg}$ compared with $0 \%$ and SBP and $6.0 \%$ DBP of non-smokers. For hyperlipidemia, smokers had $16.7 \%$ serum cholesterol, 7.3\% LDL-C, and 9.3\% TG compared with $60 \%, 8 \%$ and $14 \%$ of non-smokers, respectively.

For dietary intake assessment, smokers consumed significantly less energy from carbohydrate; fat compared to controls, while energy derived from protein did not differ between groups. Moreover, smokers consumed less dietary fiber and vitamins compared with controls.

\section{Discussion}

This is the study to identify a positive independent relationship between tobacco smoke, Passive smoking and serum vitamin B12, folate, SBP, DBP, lipid profiles MDA, $\mathrm{CD}$ and plasma homocysteine. Cigarette smoking is established as a major risk factor for coronary heart disease. The effect is caused by various factors such as sympathetic activation and inflammation [23, 24]. It has already been shown that passive smoking was linked to cardiovascular events, and in that study passive smokers were determined by interview alone [25]. Folate, vitamin B6 and vitamin B12 are involved in the regulation of homocysteine, and elevation of homocysteine has been shown to be an independent risk factor for coronary heart disease [26]. Homocysteine lies at the branch point of methionine metabolism, between the remethylation and trans-sulfuration pathway, and forms methionine and cystathionine, respectively. Hyperhomocysteinemia could be associated with the process of atheroscelosis via modification of low-density lipoprotein (LDL), a decrease in antioxidative protection, lipid peroxidation, and thrombosis. Chemical compounds found in tobacco smoke interact with the above and transform them into inactive compounds reducing their active concentration in biological fluids and possibly alter the ability of the cell to store and metabolite folate [27]. The significant lower serum folate levels in all groups of smokers (5.28-6.39 $\mathrm{nmoll}^{-1}$ ) compared with $7.84 \mathrm{nmoll}^{-1}$ of non-smokers were found in this study most likely follow the mentioned mechanism, and other studies have confirmed the finding [28, 29]. Regarding B12 levels, only group of handmade tobacco smokers had significant higher vitamin B12 (754.9 pmoll $\left.^{-1}\right)$ than non- smokers (409.22 pmoll $^{-1}$ ) whereas no significant difference between the other groups of smokers and non-smokers. The only group of industrial tobacco smokers had serum vitamin B 12 lower than non-smoker but not significantly. The explanation of this phenomenon is based on the studies on differences in lifestyle and poor dietary habits between smokers and non-smokers [30]. Industrial tobacco smokers have a lesser tendency to consume whole-wheat bread, high fiber breakfast cereals, fruits and vegetables than other groups and non-smokers. The usual dietary sources of vitamin B12 are meat and meat products, seafood, shellfish, fish, poultry and eggs. On the other hand, passive smokers and local handmade tobacco smokers (farmers and gardeners) are more likely to consume a high dietary intake. However, the method for a quantitative dietary assessment used in this investigation did not allow the measurement of folate and vitamin B12. Correspondingly were the number of cigarettes smoked per day, the industrial tobacco smokes, the time of exposure to environmental tobacco smoke, the passive smokers, and the composition of rolling paper used as a base material for local handmade tobacco. Future studies to investigate these multifactors such as lifestyle, nutritional status especially in fruits and vegetables, exposure time to environmental tobacco smoke, and composition of rolling paper that defines the role of vitamin B12, folate, lipid peroxidation and homocysteine in different smokers.

The existing literature is vague regarding the relationship between smoking and serum cobalamin levels (vitamin B12). Two studies investigating into smoking during pregnancy and vitamin status suggest that there may be a dose related relationship between smoking and the metabolism of vitamin B6 and B12 while a third study (among men only) found significantly higher B12 levels among smokers (465 pmoll ${ }^{-1}$ vs 314 pmoll $^{-1}$ ) [12, 31, 32, 33]. Although it has been stated, that elevated B12 levels among smokers might be attributed to higher meat consumption, (since smokers are more likely to choose meat instead of fruit and vegetables). A lack of dietary folic acid leads to many health problems. Folate deficiency affects the haematopoietic system, resulting in megaloblastic anemia, which is also induced by a vitamin B12 deficiency. In addition, folate deficiency has been implicated in the carcinogenesis of several tumor types, including acute lymphoblastic leukemia, breast cancer, and gastric cancer. It is known that hyperhomocystinaemia is linked to inadequate intake of vitamins, particularly B-group vitamins, and therefore may be amenable to nutritional intervention [34]. Alternatively, it may be because cigarette smokers have pooper diets than non-smokers. According to several studies, the differences in lifestyle dietary habits between smokers and non-smokers could potentially account for these disparities. Smokers tend to consume fewer fruits and vegetables as a source of these vitamins. In general, smokers are known to consume fewer food items rich in antioxidants, and tend to prefer a meat and alcohol dietary pattern in comparison to non-smokers [35, 36, 37]. A relationship between blood folate and homocysteine concentration has been reported in terms of secondhand 
exposure to cigarette smoke, ie, passive smoking. In this study, blood folate concentration was decreased in men exposed to tobacco smoke $\left(6.39 \pm 0.32\right.$ vs $7.84 \pm 1.26 \mathrm{nmoll}^{-1}$ in non-smokers). In addition to Ortega et al. study, blood folate concentration was decreased in young women exposed to tobacco smoke $\left(16.7 \pm 6.5\right.$ vs $18.4 \pm 6.7 \mathrm{nmoll}^{-1}$ in nonsmokers) [38]. Similarly, secondhand workplace exposure also increased homocysteine concentration [39]. The same result in this study, homocysteine concentration was increased in passive smokers $(17.71 \pm 0.84$ vs $14.48 \pm 0.72$ $\left.\mu \mathrm{mol} 1^{-1}\right)$. Folate and hyperhomocysteinemia are typical found in smokers, but their role in this pathophysiologic process remains controversial. Future work is clearly needed in order to comprehensively investigate and define the roles of folate and homocysteine in smokers.

\section{Conclusion}

Blood folate levels are decreased by tobacco smoking and reasonable by secondhand smoke. Low folate concentration is an independent risk factor for cardiovascular disease. The mechanism of low folate depends on the lifestyle and dietary habits, which smokers may be consuming low folate -rich fruits and vegetables. Although hyperhomocysteinemia is usually come with low folate, the significance of hyperhomocysteinemia still remains to be illustrated in smokers. Low folate and hyperhomocysteinemia are typically found in smokers and passive smokers, but their role in the pathophysiological process is still controversial. These findings indicate that passive smoke exposure in neversmokers is associated with plasma homocysteine levels in a positive and may support why passive smoking is a risk factor for cardiovascular events. Further study is needed in order to investigate lifestyle, nutritional status especially in fruits and vegetables and define the roles of folate and homocysteine in smokers.

\section{Acknowledgements}

The authors wish to express their sincere thanks to not only the volunteers from military unit of Phramongkutklao Hospital, Bangkok, but also the volunteers from a village in Phitsanulok who participated in this study. Mr. Pisan Jitthorntam (Faculty of Medicine, Mahidol University) for Biochemistry laboratory. Mr. Chaiwat Pravejthonsopon (Department of the Chemical Metrology and Biometry, National Institute of Metrology, Thailand) for the cooperation in this research. This project was supported by funds from Tobacco Control Research and Knowledge Management Center (TRC), Mahidol University and Thai Health Promotion Foundation (59-04-08, 29th Aug 2016).

\section{References}

[1] apps.who.int/gho/data/node.main.65 and United Nations. World Population prospects 1990. New York: United Nation; 1991, 226-31.
[2] WHO report on the global tobacco epidemic (2013). Tobacco fact sheet No. 339 update July 2013, http://www.who.int/mediacentre/factsheets/fs339/en/.

[3] World Bank. Development in practice-curbing the epidemic: governments and the economics of tobacco control. Washington DC. World Bank. 1999 pp. 32-3.

[4] US Department of Health and Human Services. The health consequences of involuntary exposure to tobacco smoke: A report of the Surgeon General. Atlanta, Georgia: US Department of Health and Human Services, Centers for Disease Control and Prevention, Coordinating Center for Health Promotion, National Center for Chronic Disease Prevention and Health Promotion, Office on Smoking and Health, 2006. Available from http://www.cdc.gov/tobacco/data_statistics/sgr/sgr_2006/inde $\mathrm{x} / \mathrm{htm}$.

[5] X. Lv, J. Sun, Y. Bi, et al., (2015) "Risk of all cause mortality and cardiovascular disease associated with secondhand smoke exposure: A systematic review and meta-analysis," International Journal of Cardiology 199, 106-115. Available from http://www.ncbi.nlm.nih.gov/pubmed/15911719.

[6] DS. Celemajor, MR. Adams, P. Clarkson et al., (1996) "Passive smoking and impaired endothelium-dependent arterial dilatation in healthy adults," N Eng J Med 334, 150154.

[7] EJ. Neufeld, SM. Mietus, AS. Beiser, AL. Baker, JW. Newbuger, (1997) "Passive cigarette smoking and reduce HDL cholesterol levels in children with high-risk lipid profiles," Circulation 96, 1403-1407.

[8] SG. Kavita, GN. Meeta, MG. Priyada and Gonsa RN, (2013) "Effect of smoking on lipid profile," JCRR 5, 36-42.

[9] Y. He, B. Jiang, ZH. Wan, QS. Zheng and LS. Li, (2007) "Study on the relationship between passive smoking and blood lipid, fibrinogen and viscosity among women who never smoke," Zhonghua Liu Xing Bing Xue Za Zhi 28,1167-1170.

[10] DE. Wilcken, (2002) "Homocysteine, smoking and vascular disease," Eur Heart J 23, 1559-1560.

[11] R. Meenakshisundaram, C. Rajendiran and P. Thirumalai Kolunthu Subramanian, (2010) "Lipid and lipoprotein profiles among middle aged male smokers: a study from southern India," Tobacco Induced Diseases 8, 11-15.

[12] M. F. McCarty, (2000) "Increased homocyst (e) ine associated with smoking, chronic inflammation, and aging may reflect acute-phase induction of pyridoxal phosphatase activity," Medical Hypotheses 55, 289-293.

[13] K. Pagin, J. Hou, R. L. Goldenberg, S. P. Cliver, and T. Tamura, (2001) "Effect of smoking on serum concentrations of total homocysteine and B vitamins in mid-pregnancy," Clinica Chimica Acta 306,103-9.

[14] K. S. McCully, (1969) "Vascular pathology of homocysteinemia: Implications for the pathogenesis of arteriosclerosis," The American Journal of pathology 56, 111128.

[15] M. Naruszenewicz, E. Mirkiewicz, A. J. Olszewski, and K. S. McCully, (1994) "Thiolation of low-density lipoprotein by homocysteine-thiolactone sauses increased aggregation and interaction with cultured macrophages," Nutrition, Metabolism and Cardiovascular Disease 4, 70-77. 
[16] W. J. Vermaak, H. C. Barnard, G. M. Potgieter, and H. D. Theron, (1987) "Vitamin B6 and coronary artery disease. Epidemiological observations and case studies," Atherosclerosis 63, 235-238.

[17] K. Robinson, E. L. Mayer, D. P. Miller, et al., (1995) "Hyperhomocysteinemia and low pyridoxal phosphate. Common and independent reversible risk factors for coronary artery disease," Circulation 92, 2825-2830.

[18] R. L. Stedman, (1968) "The chemical composition of tobacco and tobacco smoke," Chemistry Reviews 68, 53-207.

[19] D. F. Church, and W. A. Pryor, (1985) "Free-radical chemistry of cigarette smoke and its toxicological implications," Environmental Health Perspectives 64, 111-126.

[20] Office of Environmental Health Hazard Assessment CEPA. (1997) "Health Effects of Exposure to Environmental Tobacco Smoke," Final Draft for Scientific, Public and SRP Reviews 8, 71.

[21] J. A. Buge, and S. D. Aust, (1978) "Microsomal lipid peroxidation," Methods in Enzymology 52, 302-310.

[22] R. B. Mansour, S. Lassoued, B. Gargouri, E. A. Gaid, and F. Fakkhfakh, (2008) "Increased levels of autoantibodies against catalase and superoxide dismutase associated with oxidative stress in patients with rheumatoid arthritis and systemic lupus erythematosus," Scandinavian Journal of Rheumatology 37, 103-108.

[23] J. S. Nosanchuk, J Chang, and Bennett, J. M. (1978) “The analytic basis for the use of platelet estimates from periperal blood smears. Laboratory and clinical applications" American Journal of Clinical Pathology. Apr; 69 (4), 383-387.

[24] T. Katayama, Y. Iwasaki, N. Sakodam, and M. Yoshioka, (2008) 'The etiology of 'smoker's paradox' in acute myocardial infarction with special emphasis on the association with inflammation," International Heart Journal 49, 13-24.

[25] I. Kawachi, G. A. Colditz, F. E. Speizer, et al., (1997) “A prospective study of passive smoking and coronary heart disease" Circulation 95, 2374-2379.

[26] H. Refsum, P. M. Ueland, O. Nygard, and S. E. Vollset, (1998) "Homocysteine and cardiovascular disease," Annual Review of Medicine 49, 31-62.

[27] C. A. Northrop-Clewes, and D. I. Thurnham, (2000) "Monitoring micronutrients in cigarette smokers," Clinica Chimica Acta 377 (1-2), 14-38.

[28] R. M. Ortega, A. M. Lopez-Sobaler, Gonzalez-Gross, M. Met al., (1994) "Influence of smoking of folate intake and blood folate concentration $\mathrm{s}$ in a group of elderly Spanish men," The Journal of the American College of Nutrition 13, 68-72.

[29] CJ., M. Piyathilake, Hine, R. J Richards, E. W. and Krumdieck, C. L. (1994). "Local and systemic effect" -566 .

[30] Sobczak, A (2003) "The effects of tobacco smoke on the homocysteine level a risk factor of atherosclerosis," Addition Biology June 8,147-158.

[31] M. Milman, and M. (1999) "Relationship between serum ferritin and risk factors for ischemic heart disease in 2235 Danes aged 30-60 years" The Journal of Internal Medicine 245 (5), 423-433.

[32] S. Kim, H Shun, and C. Keen, (2003) "Influence of smoking on markers of oxidative stress and serum mineral concentrations in teenage girls in Korea," Nutrition 19 (3), 240-243.

[33] C. L. Relton, M. S. Pearce, and L. Parker, (2005) "The influence of erythrocyte folate and serum B12 status on birth weight" British Journal of Nutrition 93,593-599.

[34] J. Selhub, P. F. Jacques, P. W. Wilson, D. and I. H. Rosenberg, (1993) "Vitamin status and intake as primary determinants of homocysteinemia in an elderly population" The Journal of the American Medical Association 270, 2693-2698.

[35] C. I. Vardavas, M. K. Linardakis, C. M. Hatzis, N. Malliaraki, Malliaraki, W. H. and Kafatos, A. G., (2008) "Smoking status in relation to serum folate and dietary vitamin intake," Tobacco Induced Diseases Sep 9, 4-8.

[36] S. Voutilainen, T. H. Rissanen, J. Virtanen, T. A. Lakka, and Salonen, J. T., (2001) "Low dietary folate intake is associated with an excess incidence of acute coronary events," the Kuopio Ischemic Heart Disease Risk Factor Study Circulation 103, 2674-2680.

[37] P. Padrao, N. Lunet, A. C. Santos, and H. Barros, (2007) "Smoking, alcohol, and dietary choices: evidence from the Portuguese National Health Survey," BMC Public Health. 7, 138.

[38] R. M. Ortega, A. M. Requejo, et al., (2004) "Smoking and passive smoking as conditioners of folate status in young women" The Journal of the American College of Nutrition," 365-371.

[39] Clark. J. D., 3 ${ }^{\text {rd }}$, J. D. W. G. LeBlanc, et al., (2008). "Inflammatory markers and secondhand tobacco smoke exposure among U. S. workers," American Journal of Industrial Medicine 51, 626-632. 